\title{
A comunicação e extensão no Museu Paraense Emílio Goeldi
}

Nelson Sanjad

Doutor em História da Ciência pela Fundação Oswaldo Cruz.

Coordenador de Comunicação e Extensão do Museu Paraense Emílio Goeldi/MCT

e professor do Centro Universitário do Pará.

Resumo: $O$ texto apresenta um breve histórico do Museu Paraense Emílio Goeldi e a atual estrutura da instituição, destacando as atividades de pesquisa e comunicação. Em seguida, expõe princípios e valores sobre os quais a comunicação científica é baseada e enumera os principais serviços oferecidos pelo museu, com o objetivo de demonstrar o dinamismo e a capilaridade social da instituição.

Palavras-chave: educação não-formal, educação científica, educação ambiental, museologia, Museu Paraense Emílio Goeldi.
Abstract: The paper presents a brief chronological overview of the Museu Paraense Emilio Goeldi, and the current structure of the institution, highlighting its research and communication activities. Principles and values that form the basis for scientific communication are exposed, and the main services offered by the Museu Goeldi are listed, with the goal of demonstrating the institution dynamism and social capillarity.

Keywords: Nonformal education, Scientific education, Environmental education, Museology, Museu Paraense Emílio Goeldi

\section{UM POUCO DE HISTÓRIA}

O Museu Paraense Emílio Goeldi (MPEG), com sede em Belém (PA), é um instituto vinculado ao Ministério da Ciência e Tecnologia. Foi fundado em 1866 por um grupo de homens ilustrados, a Associação Philomatica, que pretendia instalar na capital da província um museu de história natural e de artefatos indígenas, uma biblioteca especializada nesses assuntos e um estabelecimento de instrução popular, como então se dizia, com lições (aulas) e preleções (palestras) 
regulares ao público. Em 1871, a instituição foi absorvida pelo governo da Província do Grão-Pará, mas durante todo o Império o antigo Museu Paraense teve seu funcionamento inviabilizado por discussões inócuas relacionadas à conveniência ou não de financiá-lo, promovidas por políticos pouco interessados em ciência. O museu chegou a ser extinto em 1889, mas felizmente a Proclamação da República não permitiu sua liquidação nem a dispersão do acervo.

Os políticos paraenses que assumiram o poder, de cariz positivista, incluíram a reforma do Museu Paraense em um conjunto de ações destinadas a reformar o povo, considerado ignorante e incivilizado. Aos nossos olhos, esse projeto pode ser considerado autoritário, mas nos deixou como herança novos espaços de sociabilidade e instituições atualmente valorizadas pelas ações educativas e por conservar o patrimônio cultural. Em 1891, o Museu Paraense foi reinstalado por José Veríssimo, então Secretário da Instrução Pública. Três anos depois, seria totalmente reformado pelo governador Lauro Sodré e pelo zoólogo Emílio Goeldi, contratado com esse desafio. Nessa época, a arrecadação do Estado do Pará, graças à exportação do látex, permitiu investimentos significativos em infra-estrutura urbana e na educação. Goeldi teve, portanto, condições de construir nova sede para o museu (com um horto botânico e um jardim zoológico), contratar uma equipe de cientistas bastante produtiva, instalar laboratórios, organizar expedições, formar coleções, montar exposições e publicar livros e periódicos.

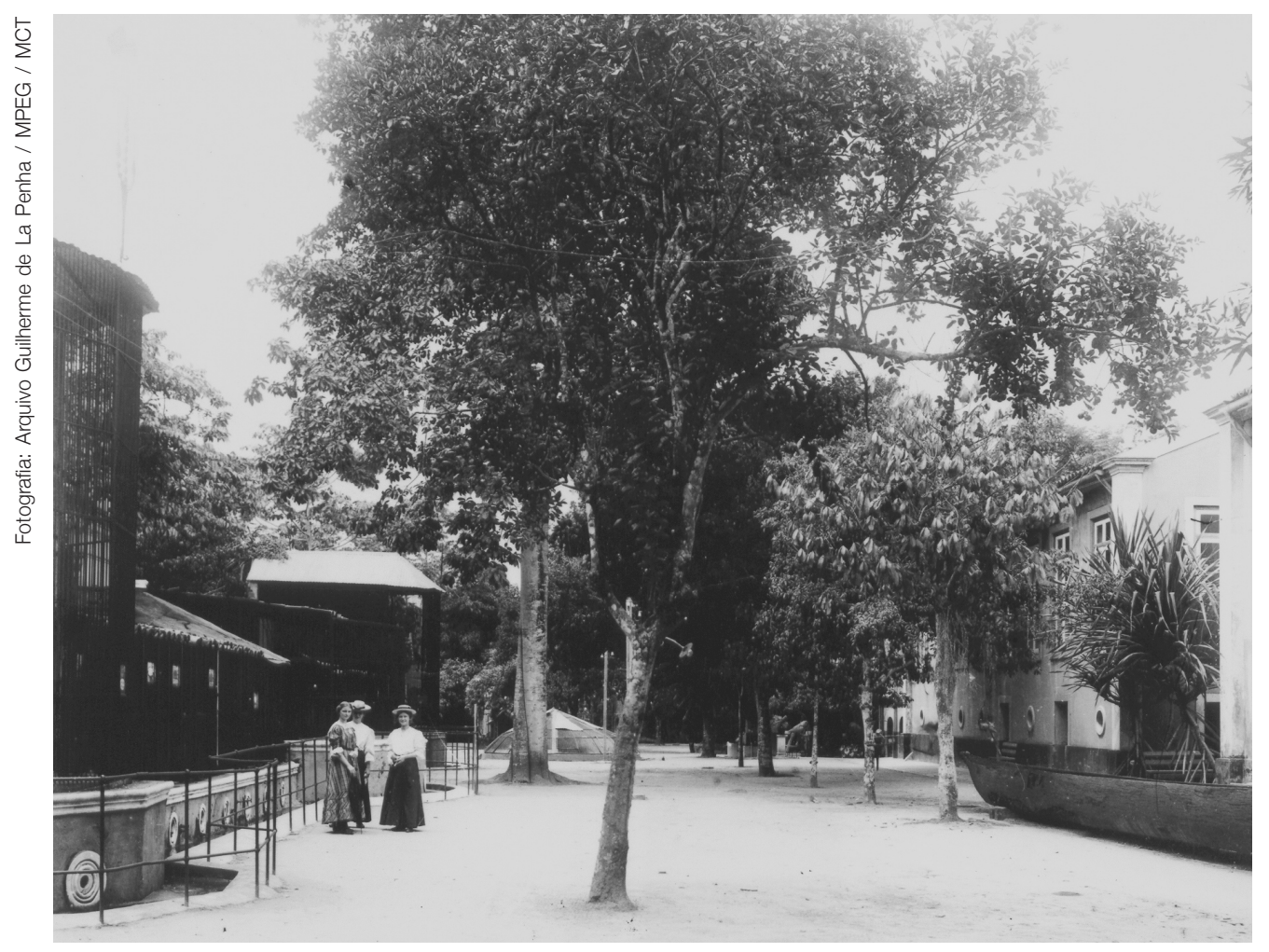

Visitantes no Parque Zoobotânico, ca. 1905. 
Esse período fértil consolidou o museu e deu a ele um lugar definitivo na memória e no processo de construção da identidade local. Desde que foi aberto, em 1895, o Parque Zoobotânico recebeu adesão imediata da população de Belém, que passou a freqüentá-lo com regularidade. O Parque atraiu $90 \mathrm{mil}$ pessoas em 1900 e 120 mil em 1907, valores correspondentes, respectivamente, às impressionantes cifras de $60 \%$ e $70 \%$ da população da cidade. Ainda hoje sua visitação é das mais altas do País, tendo recebido, em 2007, 220 mil pessoas ou $11 \%$ da população da Região Metropolitana.

Isso explica, em parte, por que o Museu Paraense, transformado em Museu Goeldi em 1900, resistiu aos momentos mais difíceis da economia paraense, como as décadas de 1920 e de 1940. Nesse intervalo, a instituição gozou de um breve período de animação, revalorizada por nova conjuntura política e econômica (Revolução de 30 e Estado Novo) e administrada com zelo e criatividade por Carlos Estevão de Oliveira.

Na década de 1950, novas discussões relacionadas à importância da ciência e tecnologia para o desenvolvimento do país posicionaram o MPEG no centro dos interesses governamentais, sobretudo após a criação do Conselho Nacional de Pesquisas (CNPq), em 1951, e do Instituto Nacional de Pesquisas da Amazônia (INPA), em 1954. Na época, a Amazônia ressurgiu como fronteira econômica e também como espaço a ser incorporado ao capitalismo mundial por meio da ciência, sendo considerada área prioritária para investimentos pela Unesco. Nesse contexto, o MPEG, com pequena infra-estrutura, mas com importantes coleções e um capital simbólico ainda ativo (e relevante para um país com tão poucas realizações no campo da ciência, até então), foi federalizado (1955) e passou a receber os investimentos necessários à sua recuperação, manutenção e ampliação.

\section{O MUSEU GOELDI HOJE}

Atualmente, a instituição possui três bases físicas. Além do Parque Zoobotânico, foram criados o Campus de Pesquisa, para onde foram transferidas as coleções e atividades científicas nas décadas de 1980 e 1990, e a Estação Científica Ferreira Penna, localizada na Floresta Nacional de Caxiuanã (PA), inaugurada em 1993. Nesse universo, transitam cerca de 600 pessoas, entre servidores públicos, bolsistas, estagiários, funcionários terceirizados e estudantes de pós-graduação, divididas nas atividades de pesquisa, comunicação e administração. O acervo soma 4,5 milhões de itens tombados em 17 coleções, o que faz do MPEG um dos maiores museus do País, ao lado do Museu Nacional/UFRJ e do Museu de Zoologia/USP. Quatro cursos de pós-graduação foram criados em convênio com instituições locais: Zoologia (UFPA), Botânica Tropical (UFRA), Ciências Sociais (UFPA) e Ciências Ambientais (Embrapa e UFPA). 


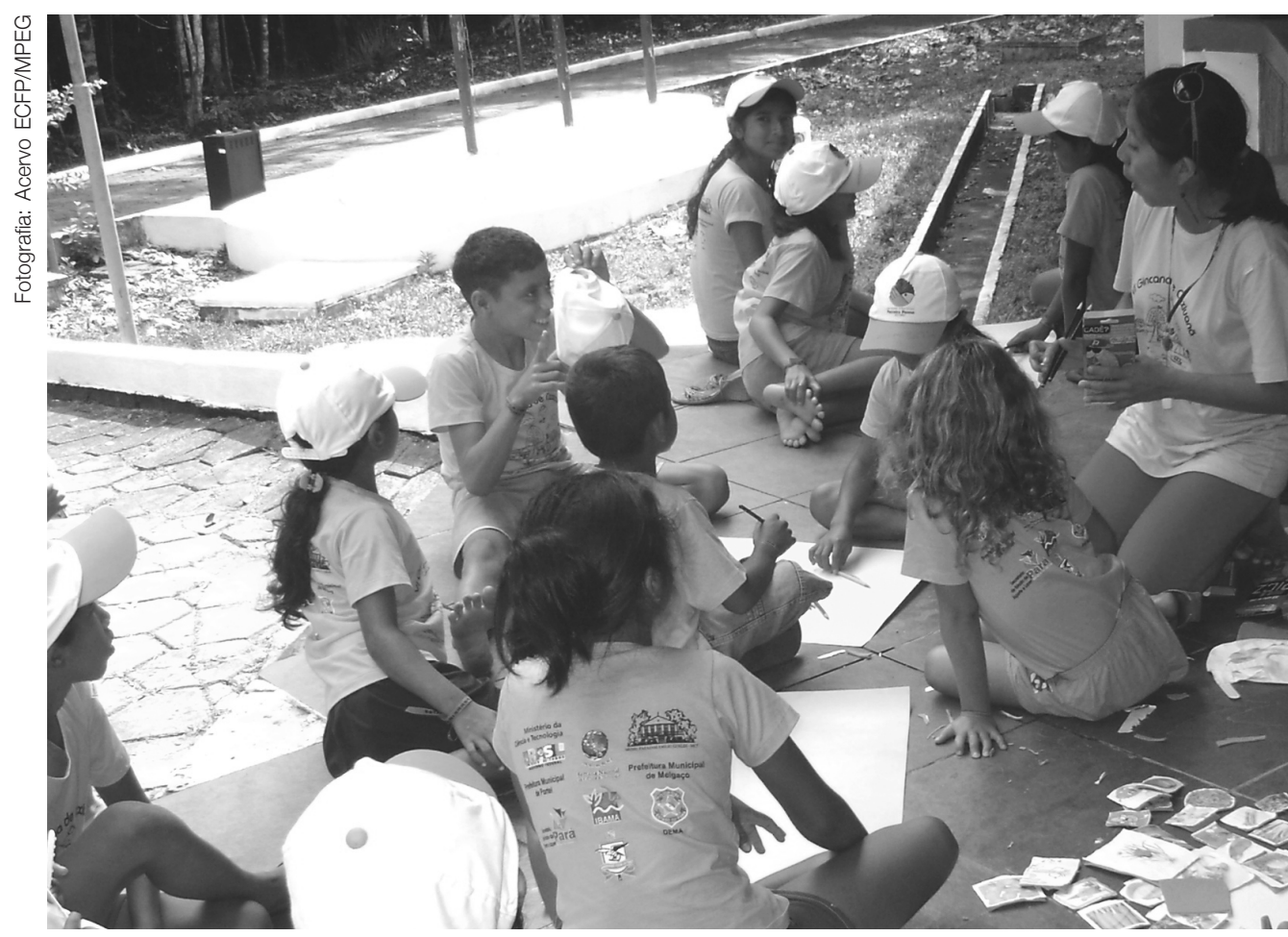

Atividade educativa na Estação Científica Ferreira Penna, Floresta Nacional de Caxiuanã.

As atividades de pesquisa e desenvolvimento tecnológico são realizadas em quatro temas distintos: sistemas naturais e diversidade biológica na Amazônia; dinâmicas socioculturais e ocupação humana na Amazônia; tecnologias de documentação, conservação e gestão de acervos científicos; e museologia, comunicação, informação e educação científica. Estas últimas, além de temas para pesquisas, são também as áreas em que o MPEG atua por meio de projetos aplicados e prestação de serviços. Esses projetos e serviços são organizados em cinco setores diferentes: Coordenação de Museologia, Coordenação de Informação e Documentação, Serviço do Parque Zoobotânico, Serviço de Comunicação Social e Editora, responsável pela publicação de livros e de dois periódicos científicos, o Boletim do Museu Paraense Emílio Goeldi, nas suas versões dedicadas às Ciências Humanas e às Ciências Naturais.

Há cerca de 100 pessoas trabalhando nas atividades de comunicação e extensão, com diversas formações e funções. Juntas mantêm os serviços oferecidos regularmente e conseguem realizar, em 10 municípios do interior do Estado, diferentes projetos.

\section{COMUNICAÇÃO E EXTENSÃO: PARA QUÊ E PARA QUEM?}

Mas o que exatamente o Museu Goeldi comunica e com quem se relaciona? A primeira resposta é a seguinte: informações e conhecimentos referentes à 
Amazônia, geralmente vinculados às atividades de pesquisa da instituição. Esses conhecimentos são adaptados de acordo com o público interessado e a linguagem a ser adotada. Por exemplo, uma exposição sobre a arqueologia do Baixo Amazonas, montada em Belém, terá um tratamento inteiramente diferenciado de um projeto de educação patrimonial executado em comunidades quilombolas do rio Trombetas, onde os objetos arqueológicos foram escavados. Em ambas as ações os objetos estarão presentes, mas cumprindo um papel diferente (e sendo interpretados pelo público de maneira diversa).

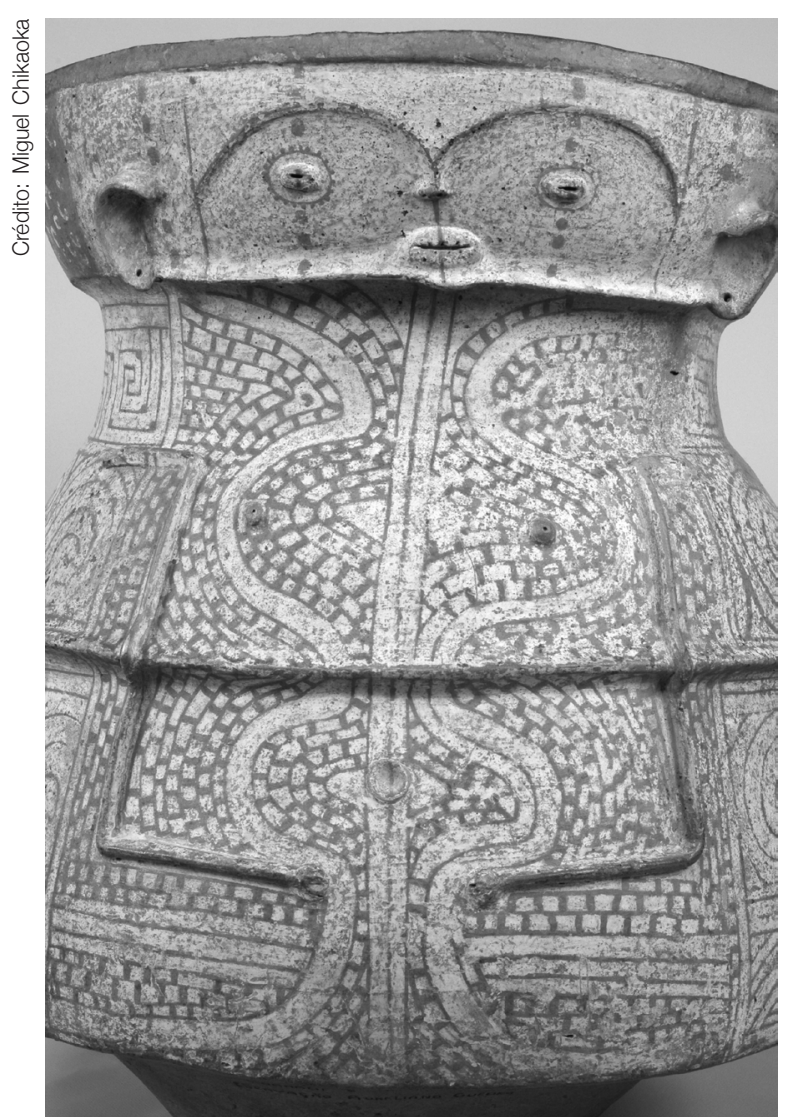

Urna funerária Cunani, AP. Acervo Arqueológico/Museu Paraense Emílio Goeldi/MCT.

O importante a destacar é que, independentemente do conhecimento em questão, o MPEG assumiu em seu Planejamento Estratégico e no seu Plano Diretor alguns princípios e valores que vale a pena mencionar. Os primeiros dizem respeito à maneira como a instituição entende a "ciência" e a "comunicação da ciência": a ciência é um patrimônio da humanidade e deve estar acessível a todos; a comunicação científica faz parte do processo de produção do conhecimento, e é direito do cidadão ter acesso ao conhecimento científico produzido com recursos públicos. Quanto aos valores, importam na maneira como as atividades são planejadas e executadas, isto é, o que elas devem ter como base ou pano de fundo: a ética na pesquisa científica; o fortalecimento da credibilidade do MPEG como instituição de ciência e tecnologia; a responsabilidade social enquanto instituição pública; o respeito e a valorização da diversidade étnica, cultural, biológica e ambiental da Amazônia.

O público do MPEG é vasto e complexo. Ele inclui desde as famílias que procuram o Parque Zoobotânico para passear nos finais de semana até o setor produtivo e os gestores públicos, que sempre demandam determinados serviços e consultorias, como inventários biológicos, salvamentos arqueológicos, planos de manejo, laudos antropológicos, cursos e treinamentos, desenvolvimento de políticas públicas nas áreas ambiental e social etc. Nesse meio também se encontram aqueles responsáveis imediatos pela produção e consumo de conhecimento, os cientistas, os professores e os estudantes (do Ensino Fundamental à pós-graduação). E também os públicos considerados especiais pela atenção 
comunicação \& educação • Ano XIII • Número 2 - maio/ago 2008

que requerem, como a imprensa e os movimentos sociais. Neste último caso, exemplificado pelas comunidades indígenas, centros comunitários, pequenos agricultores, pescadores e artesãos, há um esforço institucional e um compromisso moral de pesquisadores e técnicos em proporcionar o auxílio possível.

\section{ALGUNS EXEMPLOS DE SERVIÇOS E PROJETOS DE COMUNICAÇÃO E EXTENSÃ̃O}

\section{Parque Zoobotânico}

O Parque Zoobotânico do MPEG possui 5,4 hectares, localizados no centro de Belém. É considerado a principal área de lazer e um dos mais importantes pontos turísticos da cidade. Também é uma das principais áreas verdes, refúgio de aves e ponto de absorção de calor. Seu uso atual consiste na exposição de animais e vegetais vivos e de coleções científicas do museu, além de sediar a administração da instituição e suas atividades educativas. O Parque é tombado como Patrimônio Histórico Nacional (IPHAN) e Estadual (Secretaria de Cultura), além de ser protegido por leis municipais que o defendem do trânsito pesado e da poluição sonora.

O plantel atual do Parque é composto por várias espécies de animais amazônicos, algumas delas ameaçadas de extinção, como a onça-pintada, o coatá-da-testa-branca, a ariranha, o gavião-real, a arara-azul e a ararajuba. Em 2007, foi registrado o seguinte plantel: 286 mamíferos (13 espécies); 460 aves (44 espécies); 1.269 répteis (23 espécies); e 314 peixes (30 espécies). Houve o nascimento de 210 animais, sendo 44 mamíferos, 16 aves e 150 répteis.

O Aquário está sendo reformado e ampliado, com o apoio do Ministério do Turismo e da iniciativa privada. Quando reabrir, no segundo semestre de 2008, ele terá quatro aquários pequenos, dois médios e dois grandes, tipo glass wall, onde várias espécies conviverão em um ambiente que simulará o fundo de um rio amazônico. Haverá, ainda, dois terrários para exibição de anfíbios e um herpetário para exibição de serpentes e quelônios.

Em 2007, no âmbito do horto foram observadas 1.185 espécimes, com registro dos eventos fenológicos de floração, frutificação, maturação, dispersão, desfolha parcial, desfolha total e reenfolhamento. Foram produzidas 865 mudas de 24 espécies diferentes, algumas ameaçadas de extinção, como o mogno (Swietenia macrophylla, King) e o pau-rosa (Aniba rosaeodora, Ducke).

\section{Exposições}

Existem atualmente, no Parque Zoobotânico, cerca de $450 \mathrm{~m}^{2}$ de área expositiva, sendo 300 para a exposição de longa duração, intitulada Reencontros: 
Emílio Goeldi e o Museu Paraense, e 150 para exposições temporárias, em duas salas. Esse espaço fica no Pavilhão Domingos Soares Ferreira Penna, conhecido como Rocinha, o principal prédio do Parque, construído em 1879. Para que fosse possível a montagem das exposições, o prédio foi restaurado e adaptado entre 2003 e 2005.

Anualmente, são montadas três exposições temporárias, com temas e parceiros diversos. Mostras itinerantes também são produzidas, geralmente a partir de projetos específicos no interior do Estado.

Um dos projetos mais ambiciosos e complexos atualmente, na área de comunicação, é a construção de um novo centro de exposições, que homenageará o ex-diretor do MPEG, o antropólogo Eduardo Galvão. Ele será erguido no Parque Zoobotânico, após a demolição de dois outros prédios. Terá mais duas salas, uma com $450 \mathrm{~m}^{2}$ e outra com $350 \mathrm{~m}^{2}$, esta exclusiva para as coleções arqueológica e etnográfica. Terá também um auditório, uma cafeteria, uma reserva técnica, uma oficina e um núcleo de museografia, totalizando cerca de $1.500 \mathrm{~m}^{2}$. A construção está sendo feita com recursos do Ministério da Ciência e Tecnologia, através da Secretaria de Inclusão Social e da FINEP.

\section{Biblioteca de Ciências Clara Maria Galvão e Clube do Pesquisador Mirim}

A Biblioteca de Ciências Clara Maria Galvão (BCCMG) está localizada no Parque Zoobotânico. Foi inaugurada em 1987, em um belo prédio construído no final do século XIX. Ela reúne um acervo modesto, porém dinâmico e diversificado. São cerca de 2.500 livros, folhetos, cartilhas e periódicos. Seu diferencial consiste no acervo audiovisual e lúdico, sendo este composto por kits, jogos educativos, fantoches e cenários, que são utilizados em apresentações teatrais, exposições e feiras de ciências.

Grande parte do acervo de cartilhas, jogos e kits da BCCMG é produzido por estudantes do Clube do Pesquisador Mirim (CPM), um serviço que vem sendo oferecido pelo MPEG desde 1997, com o objetivo de estimular em estudantes do Ensino Fundamental e Médio o interesse pela iniciação científica. O CPM reúne 180 crianças/ano, organizadas em nove turmas, cada qual com um tema a ser trabalhado, baseado em pesquisas realizadas pelo MPEG. Os encontros ocorrem semanalmente e são acompanhados por monitores e pesquisadores. Não existem "aulas" propriamente ditas, e sim a mediação em tarefas teóricas e práticas, por meio das quais ocorrem os primeiros contatos com métodos e técnicas científicas. No final do ano é organizada uma feira de ciências para a apresentação dos resultados à comunidade.

\section{Coleção Didática Emília Snethlage}

O acervo científico do MPEG conserva coleções cotadas entre as mais valiosas do País, mas de acesso restrito à comunidade científica. Para atender à 
comunicação \& educação • Ano XIII • Número 2 - maio/ago 2008

demanda de professores e estudantes, que reclamam a utilização de materiais diferenciados em suas aulas, foi organizada em 1985 a Coleção Didática Emília Snethlage, com exemplares das áreas de zoologia, botânica, antropologia, arqueologia e ciências da terra.

Por meio dos 3 mil exemplares da coleção, que podem ser emprestados para professores e escolas, o estudante tem a rara oportunidade de manusear animais taxidermizados, exsicatas, réplicas de fósseis e de peças arqueológicas e artefatos indígenas. Assim é estimulado a aprender mais sobre a diversidade cultural e biológica e a debater questões relevantes para a ciência. Com freqüência os próprios técnicos da Coleção Didática são convidados ou oferecem cursos, palestras e orientação de trabalhos escolares.

\section{Prêmio José Márcio Ayres para Jovens Naturalistas}

O Prêmio José Márcio Ayres para Jovens Naturalistas foi lançado em março de 2003, pelo MPEG e pela organização ambientalista Conservação Internacional do Brasil (CI-Brasil). A iniciativa premia anualmente os seis melhores trabalhos de investigação científica de estudantes do Pará, em duas categorias: Ensino Fundamental (5 $5^{\mathrm{a}}$ a $8^{\mathrm{a}}$ séries) e Ensino Médio. Também são contemplados pelo prêmio os professores orientadores dos trabalhos, as escolas dos alunos vencedores e, a partir de 2008, os jornalistas que redigirem as melhores matérias sobre o tema Biodiversidade.

O Prêmio Márcio Ayres combina, de maneira inovadora, estratégias de educação e comunicação para ajudar a incorporar o tema no conteúdo programático das escolas paraenses. A idéia central é promover a aproximação entre ciência e comunidade escolar. Nesse sentido, o processo de mobilização para a premiação baseia-se na qualificação dos professores orientadores, sendo estes as peças-chave para estimular os estudantes ao concurso. Seguindo essa diretriz, são promovidas oficinas de capacitação para professores nas maiores cidades do Estado. Em seguida, os candidatos inscrevem seus ensaios, a Comissão Julgadora avalia os trabalhos, os melhores são considerados finalistas e estes devem ser apresentados oralmente pelos jovens naturalistas à Comissão Julgadora. Após a avaliação oral, são definidos os vencedores e, no dia seguinte, são feitos o anúncio do resultado e a entrega dos prêmios.

\section{Base de Dados de Informações Jornalísticas sobre a Amazônia: Ciência, Tecnologia e Meio Ambiente - BDIJAm}

A BDIJAm foi criada em 1996, numa iniciativa do MPEG e da Universidade Federal do Pará. Ela reúne informações sobre Ciência, Tecnologia e Meio Ambiente na Amazônia, veiculadas nos jornais locais e nos principais veículos da imprensa nacional. Os dados remontam a 1993, somando atualmente mais de 20 mil registros. Seu conteúdo está sendo preparado para ser disponibilizado 
na internet, com o apoio do Instituto de Desenvolvimento Econômico, Social e Ambiental do Estado do Pará.

O objetivo principal da Base é conservar em meios digitais a informação divulgada cotidianamente nos jornais, quase sempre perdida no dia seguinte. Nesse sentido, ela pretende ser um instrumento valioso para pesquisas sobre temas atuais ou da história recente, cujos dados ainda não foram processados pelos cientistas ou pelas instituições governamentais. São os casos, por exemplo, dos conflitos agrários e do desmatamento, com poucas fontes de informações disponíveis.

\section{CONSIDERAÇÕES FINAIS}

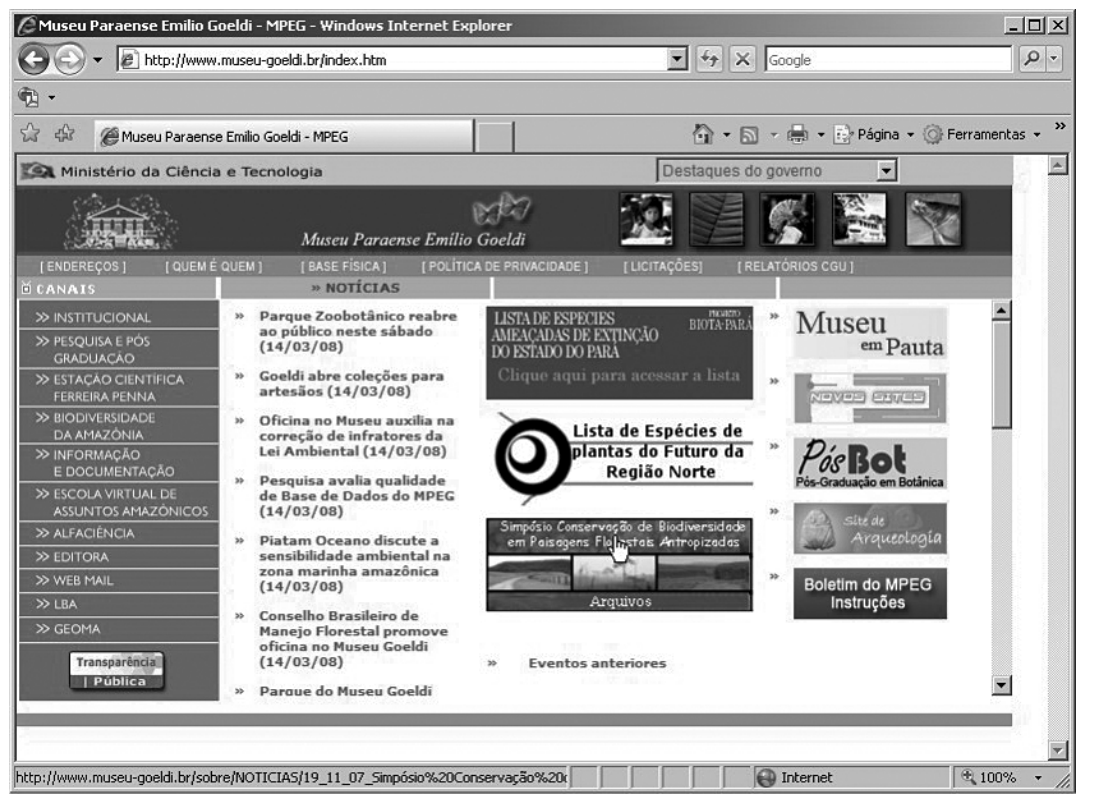

Site do Museu Paraense Emílio Goeldi/MCT.

Os serviços apresentados aqui não esgotam o universo de atividades do MPEG. A eles poderiam ser acrescentados o Núcleo de Visitas Orientadas ao Parque Zoobotânico, específico para o atendimento de escolas, que oferece regularmente cursos, oficinas e trilhas educativas; os projetos de educação patrimonial, desenvolvidos juntamente com programas de salvamento arqueológico em vários municípios; as ações que beneficiam a população da Floresta Nacional de Caxiuanã, nas áreas de educação, saúde e lazer; a Rede Ciência para a Cidadania, que capacita professores de escolas públicas e desenvolve materiais didáticos específicos para a realidade amazônica; o programa EducAmazônia, que também capacita professores e multiplicadores com o objetivo de melhorar o ensino público em comunidades rurais; e as atividades do Núcleo de Inovação e Transferência de Tecnologia, preocupadas em capacitar lideranças comunitárias na área de propriedade intelectual e conhecimentos tradicionais. 
comunicação \& educação • Ano XIII • Número 2 • maio/ago 2008

Os exemplos dados, contudo, dão a dimensão do trabalho realizado pelo MPEG, tanto no que se refere ao público atendido quanto ao número de parceiros envolvidos nessas atividades. Essa é uma característica sui generis do MPEG. Ao mesmo tempo em que desenvolve pesquisa básica, a capilaridade da instituição lhe permite articular redes e desenvolver projetos para a intervenção social.

\section{SERVIÇO}

\section{Museu Paraense Emílio Goeldi}

Av. Magalhães Barata, 376 - São Brás - Belém-PA

Agendamento de visita: Núcleo de Visitas Orientadas, telefone (91) 3259-6588.

Site: <http://www.museu-goeldi.br>. 